\title{
Exploit Ecological and Humanistic Advantages of Shilou County and Expand the Way to Achieve Prosperity for Whole Domain Tourism

\author{
Qunfang Zhu
}

Beijing Wuzi University, Beijing, China.

Keywords: Shilou County, four-color, bronze culture.

\begin{abstract}
There are "yellow, red, green, cyan" characteristic tourism resources in Shilou County, namely loess amorous feelings, red culture, green ecology, the bronze culture, but they dose not bring invaluable assets. The reason is not only lack of talents and funds, limited transport infrastructure, but also development ideas, planning and design are not in place, enhancement of the top-level design is proposed, four-color scenic spot and cultural integration and experience are built, and development of full views and whole domain tourism will go to the way of getting rid of poverty.
\end{abstract}

\section{Introduction}

With the aggravation of environmental pollution, acceleration of the pace of life, growing of working pressure and many sub-health problems, people begin to realize the importance of environmental protection. Eco-tourism caters to people's hope to integrate into nature, advocate and return to nature, and find the experience of traditional cultural needs of original ecology, which meet the demands of recuperating mind and body. Traditional tourism way have not been met the high-end demands of the people, ecotourism as a new kind of tourism pattern to protect nature, which is growing at an average annual rate of $20 \%$ to $25 \%$, and it is the fastest growing in the tourism industry. Although lucid waters and lush mountains are said to be invaluable assets, many original ecological poverty-stricken counties are still poor, and it is urgently needed to deeply analyze and study how to give play to ecological and cultural resource advantages well to overcome poverty and achieve prosperity.

\section{Development of Ecotourism Abroad}

"Ecotourism" is first proposed by American scholars Hetzer in 1965, which was first defined by Ceballas-Lascurain, special consultant of International Union for Conservation of Nautre (IUCN) in 1983: "tourists are located in relatively primitive natural areas, learn, appreciate and enjoy the scenery, wildlife and local ancient and modern cultural". Ecotourism emerged in the 1960s, which was valued by all countries in 80 s and flourished. Developing ecological tourism products with its own characteristics, the most representative is the tropical forest tourism in Costa Rica, Canada's national park, Kenya wildlife tour, etc., they has entered the mature stage now, the benefit of the ecotourism improve. According to the estimation of the World Tourism Organization, ecotourism income now accounts for $15 \%$ to $20 \%$ of the total

Tourism income in the world, and western tourists are beginning to move from materiality enjoyment to spiritual experience.

\section{China's Ecotourism Integrate and Develop Extensively}

The ecotourism is defined by "National Ecotourism Demonstration Zone Construction and Operational Standard"[1]: "the sustainable development as concept, protection of the ecological environment as the prerequisite, overall arrangement of harmony between man and nature as the guiding principle, and rely on the good natural ecological environment and unique humane ecological system, friendly ecological ways are adopted, ecological experience, education, cognition are developed and tourism ways with physical and mental pleasure are obtained." As a concept, ecotourism permeates the development and design of various tourism products. China's ecological 
tourisms developed mainly based on in natural reserves, forest park, scenic spots and so on, form has from the original natural landscape to half artificial ecological landscape, tourism objects include fields, glaciers, natural reserves and rural countryside landscape and so on, ecological tourism ways including sightseeing, tour, expedition, scientific research, adventure, fishing, hunting, rural picking and ecological agriculture subject experience activities, which present a extensive and diversified pattern.

\section{Advantages of the Ecological and Cultural Resources in Shilou County}

Taking Shilou County as an example and carry out resource analysis, Shilou County of Shanxi Province is China's national state-level poverty-stricken county. The original ecological and cultural tourism resources are rich, which are represented by "Chessboard Mountain, the Yellow River Miraculous Bay, Mao Zedong's poems and bronze culture", and have the resources advantages of the four-color culture tourism development.

\subsection{Green Ecological Resources Consider the Chessboard Hill as First}

The suitable forestland of County is 1.3 million mu. It has completed 0.678 million mu of farmland reforesting, almond forest 0.488 million $\mathrm{mu}$, the red dates forest 0.272 million mu, the walnut forest 0.165 million mu. It is the largest county in Shanxi Province that has returned the grain plots to forestry and per capita economic forest area. Forest acreage is $19.8 \%$, and forest greening rate is 46.5\%. The domestic environment is beautiful; the air is fresh, blue sky and green land, beautiful landscape in county. There are miraculous products; abundant famous spring, well-known; tribute red dates and famous in China.

Chessboard Hill forest is a national 4A level scenic spots, which has a wonderful masterpiece of nature, and it belong to the original forest belt, many rocks stagger and overlap, mountains and rivers are magnificent, history has been recorded that it is the birthplace of the sage of antiquity and the site where Nvwa mend the heaven and it is also a famous ancient battlefield and old east way.

\subsection{The Most Beautiful Miraculous Bay Witnesses Great Man's Epic Poem}

Yellow River Miraculous Bay is the most beautiful bay in the 99 bend of the Yellow River, which is $8 \mathrm{~km}$ circumference and 360 degrees like circle; it is a rare natural beauty. Mao Zedong led army and fought in this place three times, during the eastern expedition of Red Army, they cross the Yellow River through "Xinguan" ferry in upstream of Miraculous Bay, Mao Zedong commanded the important Guanshang and Pengmen battle in easter expedition, held meetings western Shanxi conference, wrote a poetic masterpiece through the ages in Li village-" Snow Adopted After the Tune of Chin Yuan Chun", left the footprints of great men's battles, and it is worth people stopping to indulge in reveries.

\subsection{The Traceable Bronze Culture is Mysterious and Stately}

As early as the Neolithic period, there is human to survive, and created the immortal civilization belonging to Yangshao culture and Longshan culture. The ancient cave which built by "timber as the nest" and houses by cliffs have changed the way of human habitation, and it is an epoch-making change. Shilou is one of the fang countries in Yin and Shang period, which has reached the peak stage. In the past years, there is 300 pieces unearthed of Yin and Shang bronze ware with quantity, variety, high grade, the historian circle called it as Yin and Shang bronze ware of Shilou type, there are 56 pieces of first-level cultural relics. The most representative dragon wine vessel is the most precious, which belongs to the rare treasure. it is the birthplace of folk legend Jiang Taigong, the most amazing ancient buildings and bronze relics constituted the unique tourism resources. Temple of goddess is the only stage of Yuan Dynasty in the Lvliang Mountain, and it is the smallest Yuan Dynasty stage home.

\section{Development Obstacle of the Whole Domain Tourism in Shilou County Ecological Culture}

The Shilou County keeps lucid waters and lush mountains but not obtain the invaluable assets. The main reasons are vicious circle of poverty, shortage of funds, lack of innovative planning management talents, conservative tourism development ideas, cause dwsign of scenic spots to lack creativity and 
the layout is decentralized, the amusement content of the scenic spots is poor without a systematic integration. Lack of tourism market conditions to gather popularity, scenic spots and operation management modes are difficult to retain people. Although there are many natural, historical and cultural resources, but not open the highway, which severely restricted the development, attracting tourist is difficult, there are not enough supporting facilities around the hotel in county, service consciousness is not strong, management level is not high, accommodation ability is weak, it is unable to drive the appreciation of related industrial chain value-added, and they become the main causes that tourism unsupport.

\section{Countermeasures and Suggestion of Creating Beautiful Shilou Whole Domain Tourism}

Although the Shilou County is poor because there is no decent industry, in fact, it is very difficult to achieve balance between industrial development and natural resources protection. It is better to expand the development of ecotourism resources, firmly establish the "lucid waters and lush mountains are invaluable assets" resource viewpoint, establish tourism industry promotion group, gather and train talents, improve traffic conditions, create new tourism projects, attract leading enterprise' investment, and promote tourism industrialization become a new breakthrough in poverty alleviation work. Specific suggestions are as follows:

\subsection{Introduce the Latest Design Concept to Do Top Design of Tourism Well.}

Based on "red, yellow, green, cyan" four-color tourism resource advantages, protect ecological environment, exploit resource potential, arrange the small-micro service subject cultivation and build leading tourist attractions fine lines, arrange online overall view of Shilou and offline stone Shilou county development, integrate resources, strengthen whole domain tourism and panoramic experience development. To build the products of the tourism 4.0 eras, achieve the cultural integration and mold cultural height, integrate and upgrade tourism experience, and operation mode of compound innovation of products. A high starting point plan, the overall top-level design, perfect the four-color tourism landscape, adopt the tourism project and fine lines as the main body, combine point with line, drive the promotion and development of tourism area, phased development, advance step by step, four-color scenic area with scientific layout, integrate four kinds of cultural elements, overall launch series of tourism products of Shilou. Recommend four types of cultural services, advocate panoramic experience, new ideas of whole domain tourism development, the scenic spots, and cultural experience are brought into Lvliang area, and even tourism network system in Shanxi Province, gradually beautiful Shilou brand that integrate scene, vacation and experience.

\subsection{Integrate Culture to Improve the Taste of the Four-Color Scenic Spots.}

Four-color scenic spots, namely "yellow scenic spot" that focuses on creating the first bay of Yellow River in western Xinguan township, "green scenic spot" of Chessboard Hill in the eastern Longjiao township," "red scenic spot special line" of eastern expedition and "cyan spots" of bronze ware tour .

In the Yellow River Miraculous Bay, we plan to build the experience zone of the Hejiawa crossing river, support the addition of the whole line simulation game and other projects, increase the experience and interaction elements, and apply modern technology means to let tourists immerse themselves in the scene and feel the eastern expedition of red history. To speed up the eastern expedition memorial hall, Liu village, Zhang Jiata, Xiwei, Luo village and Mao Zedong Road real landscape garden construction, make full use of television drama "Red Army Expedition East" influence, and gradually restore the process of eastern expedition, and actively promote the eastern expedition red tourism lines. The service quality of scenic spots of chessboard hill leisure tourism is improved, "four wonders and six scenes" constructions are highlighted, the landscape supports of surrounding industry are strengthened, scenic spots with ten thousand mu walnut orchard, farms, orchards, plants, and picking fields develop together, a concerted effort are made, ecological sightseeing tour basis are constructed. Shilou cultural museum "cyan tour" scenic spot is made. Collected bronze ware as the core, AR and VR technology are introduced, dig up the history of Jiang Taigong, integrate ancient myth and ancient cultural relics, explore the Yellow River culture and the loess culture connotation, the Shilou cultural museum are made into important places display cultural 
relics of Yellow River culture research and folk cultural exchange. Renovate Jiang Taigong and strengthen the function of leisure.

\subsection{Realize Panoramic Experience and Make Whole Domain Tourism}

The construction of the digital system of panoramic Shilou is realized by means of Internet. The holiday and consumption ideas should survive in Internet age; protect original style tourism elements of the county, the four-color culture, human landscape, cave dwelling life, fragmented landform and so on as products for leisure tourists. The tourism domain of Shilou is compared to a dragon which will take off, tourist area core of Xinguan township is the first miraculous bay of the Yellow River and as dragon's eye, Longjiao township tourist area regard chessboard hill core area as dragon's tail, Shilou cultural museum as the dragon's waist, eastern expedition red tourist special line as the dragon's body, all blend into one harmonious whole. Creating conditions to promote the deep tourism, exploiting potential and adding holiday function, extending the value chain tourism industry, and implementing tourism "+ Internet" action plan.

The development ideas of whole domain tourism are set up. The Internet leisure vacation, whole domain tourism, he concept of consumption experience ideas actively prepare to construct transportation, scenic spots, shopping guide center and other tourism services infrastructure, uniformly establishing guidance and marking system of clear tourism route, uniformly making county tourist maps, plan to the festival activities of tourism development in Shilou, helping film and television works, implement soft advertisement placement of tourist attractions and services, get widely publicized multiplier and sensational effects, attract tourists to explore their interests and promote deep tourism projects to final implementation. Implement whole staff service, whole people' reception, full-course experience action plan, promote the optimization and improvement of tourism resources, related services, ecological environment, institutional mechanism and civilization quality, attract visitors with different types, time periods and needs. The Yellow River miraculous bay, cave dwelling culture, Loess Plateau, eastern expedition line, landscape, folk life and so on are integrated, explore and enhance vacation functions, improve experience satisfaction, expand value chain of tourism industry, promote the leapfrog development of tourism and achieve casting off poverty to get rich.

\section{Acknowledgements}

Thanks to the other members of the third five-year Plan Project team in Shilou County.

\section{References}

[1]. The National Tourism Administration, tourism ecological demonstration area of environmental protection department. The national construction and operation regulations (gb/t26362 - 2010) scores. Notice rules for the 201209 month 29 days,p1. 